Revista Brasileira de Cartografia

ISSN 1808-0936 | https://doi.org/10.14393/revbrascartogr

Sociedade Brasileira de Cartografia, Geodésia, Fotogrametria e Sensoriamento Remoto

\title{
Avaliação dos Novos Parâmetros de Transformação entre ITRF (IGS) e SIRGAS2000 no IBGE-PPP com Análise de Séries Temporais
}

\author{
Evaluation of the New Transformation Parameters between ITRF (IGS) and SIRGAS2000 \\ at IBGE-PPP with Time Series Analysis
}

Lécio Alves Nascimento ${ }^{1}$, William Rodrigo Dal Poz ${ }^{2}$ e Krisley Xavier Soares de Freitas ${ }^{3}$

1 Instituto Federal de Educação, Ciência e Tecnologia do Norte de Minas Gerais (IFNMG) -Campus Araçuaí -MG, Brasil, lecio.nascimento@ifnmg.edu.br

ORCID: https://orcid.org/0000-0003-2499-4372

2 Universidade Federal de Viçosa (UFV), Departamento de Engenharia Civil, Viçosa -MG, Brasil, william.dalpoz@ufv.br ORCID: https://orcid.org/0000-0001-9532-3643

3 Universidade Federal de Viçosa (UFV), Departamento de Engenharia Civil, Viçosa -MG, Brasil, krisley.freitas@ufv.br ORCID: https://orcid.org/0000-0001-8453-324X

Recebido:10.2020 | Aceito: 12.2020

Resumo: O IBGE-PPP, serviço de Posicionamento por Ponto Preciso (PPP) online, estima coordenadas originalmente referenciadas às materializações do ITRF (IGS) e então as compatibiliza para o SIRGAS2000 com a aplicação da transformação de Helmert e seus respectivos parâmetros de transformação. Em 17 de maio de 2020 o IBGE-PPP passou a utilizar um novo conjunto de parâmetros (P2), descontinuando o conjunto antigo (P1). Nesse contexto, este trabalho se propõe a avaliar os impactos dos novos parâmetros na compatibilização de referenciais e redução de coordenadas utilizados pelo IBGE-PPP, fundamentando-se em análise de séries temporais de dados de duas estações da RBMC, NAUS e AMCO. Analisando as séries temporais SIRGAS2000 compatibilizadas com P1 (SCP1) e P2 (SCP2) para as duas estações, observou-se que as séries de componentes norte $(\Delta n)$ SCP1 apresentaram mudanças de nível (diferenças) de aproximadamente $\pm 0,017 \mathrm{~m}$ e $-0,013 \mathrm{~m}$ em relação a $\mathrm{SCP} 2$, nos períodos referentes às materializações do ITRF2005 (IGS05) e ITRF2014 (IGS14). As séries de componentes leste $(\Delta e)$ e vertical $(\Delta u) \operatorname{SCP} 1$ também apresentaram diferenças quando comparadas à SCP2, porém com magnitudes entre 0,001 m e 0,006m e 0,004 m e 0,012 m, respectivamente. Considerando os conjuntos de parâmetros de transformação entre as materializações ITRF (IGS) e SIRGAS2000, pôde-se observar que as séries SCP2 apresentaram resultados mais consistentes quando comparadas às séries SCP1, diminuindo os impactos causados pelas trocas de referenciais ocorridas ao longo do tempo. Ademais, as séries SCP2 foram compatíveis com as séries referenciadas ao ITRF2014 (IGS) ao nível menor ou igual a $0,002 \mathrm{~m}$.

Palavras-chave: IBGE-PPP. Geodésia. Helmert. Séries temporais. Parâmetros de transformação.

\begin{abstract}
The IBGE-PPP, online Precise Point Positioning (PPP) service, estimates coordinates originally referenced to the materializations of the ITRF (IGS) and then make them compatible for SIRGAS2000 with the application of the Helmert transformation and its respective transformation parameters. On May 17, 2020, IBGE-PPP started using a new set of parameters (P2), discontinuing the old set (P1). In this context, this work aims to assess the impacts of the new parameters on the compatibility of references and update of coordinates used by IBGE-PPP, based on the analysis of time series of data from two stations of RBMC, NAUS, and AMCO. Analyzing the time series SIRGAS2000 compatible with P1 (SCP1) and P2 (SCP2) for the two stations, it was observed that the series of north components $(\Delta n)$ SCP1 showed level changes (differences) of approximately $\pm 0.017 \mathrm{~m}$ and $-0.013 \mathrm{~m}$ in relation to SCP2, in the periods referring to the materializations of ITRF2005 (IGS05) and ITRF2014 (IGS14). The series of este $(\Delta e)$ and vertical $(\Delta u)$ SCP1 components also showed differences when compared to SCP2, but with magnitudes between $0.001 \mathrm{~m}$ and $0.006 \mathrm{~m}$ and $0.004 \mathrm{~m}$ and $0.012 \mathrm{~m}$, respectively. Considering the sets of transformation parameters between the ITRF (IGS) and SIRGAS2000 materializations, it was observed that the SCP2 series showed more consistent results when compared to the SCP1 series, reducing the impacts caused by the exchange of references that occurred over time. In addition, the SCP2 series were compatible with the series referenced to ITRF2014 (IGS) at a level less than or equal to $0.002 \mathrm{~m}$.
\end{abstract}

Keywords: IBGE-PPP. Geodesy. Helmert. Time series. Transformation parameters. 


\section{INTRODUÇÃO}

A tecnologia GNSS (Global Navigation Satellite Systems) tem sido amplamente empregada para finalidades distintas, tais como: monitoramento de estrutural, determinação de deslocamentos e deformações de placas tectônicas, apoio para mapeamento, georreferenciamento de imóveis rurais, etc. Dentre as alternativas de métodos de posicionamento GNSS disponíveis pode-se evidenciar o Posicionamento por Ponto Preciso (PPP). Seu destaque em relação aos demais métodos se dá, dentre outros fatores, pela disponibilidade e gratuidade de serviços de PPP online, praticidade, alta acurácia (centimétrica), independência de estações de referência, exigência apenas do arquivo RINEX (Receiver Independent Exchange Format) das observações etc. (GHODDOUSI-FARD; DARE, 2006; MOREIRA, 2010; GRINTER; ROBERTS, 2011).

Diante dos principais serviços de PPP online disponibilizados encontra-se o IBGE-PPP (Instituto Brasileiro de Geografia e Estatística - PPP). Este serviço consiste em uma adaptação do CSRS-PPP (Canadian Spatial Reference System - PPP) para uso no Brasil e fornece aos usuários resultados acurados tanto na materialização do ITRF (IGS) (International Terrestrial Reference Frame) (International GNSS Service) quanto no SIRGAS2000 (Sistema de Referência Geocêntrico para as Américas 2000), sistema de referência oficial brasileiro (RAMOS; DAL POZ; CARVALHO, 2016; IBGE, 2017).

Originalmente as coordenadas estimadas no IBGE-PPP são referenciadas à materialização do ITRF (IGS) referente às orbitas dos satélites, na época de coleta dos dados. Dessa forma, para referenciar tais coordenadas ao SIRGAS2000, é necessário que se efetue a compatibilização dos referenciais aplicando-se a transformação de Helmert, com seus respectivos parâmetros de transformação (SAPUCCI; MONICO, 2001; CARVALHO, 2015). Salienta-se que o conjunto de parâmetros utilizados pelo IBGE-PPP são os determinados e disponibilizados pelo próprio IBGE (Instituto Brasileiro de Geografia e Estatística), estimados através de coordenadas de estações GNSS permanentes localizadas no continente Sul-Americano e presentes nas realizações ITRF e SIRGAS (IBGE, 2017). Caso a compatibilização ocorra entre as materializações do ITRF (IGS), aplica-se à transformação de Helmert os conjuntos de parâmetros disponibilizados em Petit e Luzum (2010), Altamimi, Collilieux e Métivier (2012), Altamimi et al. (2016), etc.

Diversos estudos associados à compatibilização de referenciais e a atualização/redução de coordenadas utilizam com frequência a transformação de Helmert com os conjuntos de parâmetros disponibilizados por Petit e Luzum (2010), Altamimi, Collilieux e Métivier (2012), Altamimi et al. (2016), dentre estes: Carvalho, Dal Poz e Larocca (2015), Carvalho (2015); Braga e Dal Poz (2017), Braga e Dal Poz (2019), etc. Além dos parâmetros anteriores, Carvalho et Al. (2015) e Ramos, Dal Poz e Carvalho (2016) utilizam os parâmetros próprios do IBGE nos procedimentos supracitados.

IBGE-PPP (2020) destaca que a partir de 17 de maio de 2020 passou-se a utilizar um novo conjunto de parâmetros de transformação entre as materializações do ITRF (IGS) e o SIRGAS2000, o que acarretou alterações nas coordenadas, quando comparadas às determinadas com o conjunto de parâmetros utilizados anteriormente a esta data. Portanto, se mostra importante avaliar as variações ocorridas nas posições de pontos específicos, estimadas com ambos os conjuntos de parâmetros utilizados no IBGE-PPP, uma vez que estas podem influenciar negativamente a acurácia dos levantamentos geodésicos de alta precisão e/ou a atualização de produtos geodésicos/cartográficos destes derivados. Ademais, averiguar o alinhamento e similaridade entre as soluções referenciadas ao ITRF (IGS) e ao SIRGAS2000 contribuirá para dirimir dúvidas quanto à escolha do referencial a ser adotado no desenvolvimento de investigações cientificas.

Nesse contexto, propõe-se neste trabalho avaliar os impactos dos novos parâmetros entre ITRF (IGS) e SIRGAS2000 utilizados pelo IBGE-PPP na compatibilização de referenciais e redução de coordenadas, fundamentando-se em análise de séries temporais.

\section{SÉRIES TEMPORAIS POSICIONAIS}

Um conjunto de valores de posições (coordenadas) associadas a um sistema de referência e ordenadas no tempo define uma série temporal posicional. Nesse sentido, variadas metodologias podem ser utilizadas para construí-las ou obtê-las. Dentre tais metodologias, destacaremos a implementada por Nascimento et al. (2017) no programa computacional denominado RINEX EDITION. Tal programa viabiliza a construção de 
séries temporais de informações posicionais (coordenadas cartesianas $X, Y, Z$; elipsoidais $\varphi, \lambda, h$ e as precisões de ambas) a partir de dados GNSS das estações da RBMC (Rede Brasileira de Monitoramento contínuo dos Sistemas GNSS) (RBMC, 2020; COSTA et al., 2018) em conjunto com o serviço online IBGE-PPP (IBGEPPP, 2020). Caso necessário, é possível editar os arquivos RINEX de forma automatizada utilizando o TEQC (Translation, Editing and Quality Check) (ESTEY; MEERTENS, 1999; UNAVCO, 2020).

Como mencionado anteriormente, o IBGE-PPP é uma adaptação do CSRS-PPP (NRCAN, 2020) (versão 1.05/11216 atualizada) para uso no Brasil e fornece resultados acurados tanto na materialização do IGS referente à época de coleta dos dados (atualmente IGb14, compatível e alinhado com o ITRF2014) quanto no SIRGAS2000. Adicionalmente, também são disponibilizadas as coordenadas em SIRGAS2000 na data de realização do sistema, época 2000,4 (IBGE, 2017; IBGE-PPP, 2020). Salienta-se que o SIRGAS2000 é o sistema de referência oficial brasileiro e deve ser adotado em todas as atividades de informações geoespaciais (IBGE, 2015; INDE, 2020).

Originalmente, as coordenadas estimadas no IBGE-PPP estão referenciadas ao ITRF (IGS) (sistema utilizado nas órbitas IGS), época de coleta dos dados, cujas realizações aplicadas são apresentadas na Tabela 1.

Tabela 1 - Soluções IGS adotadas pelo IBGE-PPP.

\begin{tabular}{l|c}
\hline Data de rastreio GNSS & Realização IGS \\
\hline $05 / 11 / 2006$ a $16 / 04 / 2011$ & IGS05 \\
$17 / 04 / 2011$ a $06 / 10 / 2012$ & IGS08 \\
$07 / 10 / 2012$ a $28 / 01 / 2017$ & IGb08 \\
$29 / 01 / 2017$ a $16 / 05 / 2020$ & IGS14 \\
$17 / 05 / 2020$ a atualmente & IGb14 \\
\hline
\end{tabular}

Fonte: IBGE (2017) e IBGE-PPP (2020).

As realizações utilizadas pelo IGS em seus produtos são alinhadas e compatíveis com as materializações dos ITRFs, compartilhando a mesma origem, escala e orientação (IGSACC, 2020). Cabe salientar que o IGb08 é uma atualização do IGS08, assim como o IGb14 é uma atualização do IGS14 e visam estabilizar o alinhamento dos referenciais dos produtos IGS, sem alterações aos usuários (REBISCHUNG, 2012; REBISCHUNG, 2020).

Dentre as materializações do ITRF (IGS) destaca-se como a mais consistente a do ITRF2014 (IGS14), justificável pela consideração de movimentos não lineares das estações, incluindo sinais sazonais (anuais e semestrais) de posições de estações e deformação ocorridas após eventos sísmicos causados por grandes terremotos (ALTAMIMI et al., 2016). De forma análoga, encontra-se em desenvolvimento atualmente o ITRF2020 (ITRF, 2020).

Na sequência, as coordenadas referenciadas às materializações do ITRF (IGS) são compatibilizadas para o SIRGAS2000 aplicando-se a transformação de Helmert, com os respectivos parâmetros de transformação (três translações, um fator de escala e três rotações) entre ITRF (IGS) e SIRGAS2000 disponibilizados pelo IBGE. Como não são disponibilizadas as variações temporais destes parâmetros, não há necessidade de atualização destes para a época de coleta dos dados e, portanto, aplica-se o modelo apresentado na Eq. (1) (PETTIT; LUZUM, 2010):

$$
\left[\begin{array}{l}
X \\
Y \\
Z
\end{array}\right]_{d\left(t_{0}\right)}=\left[\begin{array}{l}
X \\
Y \\
Z
\end{array}\right]_{o\left(t_{0}\right)}+\left[\begin{array}{l}
T_{X} \\
T_{Y} \\
T_{Z}
\end{array}\right]_{t_{0}}+\left[\begin{array}{ccc}
D & -R_{Z} & R_{Y} \\
R_{Z} & D & -R_{X} \\
-R_{Y} & R_{X} & D
\end{array}\right]_{t_{0}}\left[\begin{array}{l}
X \\
Y \\
Z
\end{array}\right]_{o\left(t_{0}\right)}
$$

em que $d$ é o sistema de referência de destino, $o$ é o sistema de referência de origem, $T_{X}, T_{Y}$ e $T_{Z}$ são as translações em $X, Y$ e $Z$ entre os dois referenciais, dadas em metros; $D$ é o fator de escala entre os dois referenciais, adimensional, dado em partes por bilhão - ppb; $R_{X}, R_{Y}$ e $R_{Z}$ são as rotações diferenciais em torno dos eixos $X, Y$ e $Z$, dadas em radianos; $t_{o}$ é a época referente as coordenadas no sistema de referência de origem.

Para os casos em que a compatibilização entre as materializações do ITRF seja necessária, utiliza-se os parâmetros de transformação disponibilizados por Petit e Luzum (2010), Altamimi, Collilieux e Métivier 
(2012) e Altamimi et al. (2016), com suas respectivas variações temporais. Portanto, deve-se inicialmente atualizar os parâmetros de transformação de sua época $\left(t_{k}\right)$ para a época $\left(t_{o}\right)$ referente as coordenadas no sistema de referência de origem (o) conforme Eq. (2) (SAPUCCI; MONICO, 2001; PETTIT; LUZUM, 2010; CARVALHO, 2015):

$$
\vec{P}_{t_{o}}=\vec{P}_{t_{k}}+\vec{P}_{t_{k}}\left(t_{o}-t_{k}\right) \rightarrow\left(\begin{array}{c}
T_{X} \\
T_{Y} \\
T_{Z} \\
D \\
R_{X} \\
R_{Y} \\
R_{Z}
\end{array}\right)_{t_{o}}=\left(\begin{array}{c}
T_{X} \\
T_{Y} \\
T_{Z} \\
D \\
R_{X} \\
R_{Y} \\
R_{Z}
\end{array}\right)_{t_{k}}+\left(\begin{array}{c}
\dot{T}_{X} \\
\dot{T}_{Y} \\
\dot{T}_{Z} \\
\dot{D} \\
\dot{R}_{X} \\
\dot{R}_{Y} \\
\dot{R}_{Z}
\end{array}\right)_{t_{k}}\left(t_{o}-t_{k}\right)
$$

em que $\vec{P}_{t_{o}}$ é o vetor dos parâmetros de transformação na época das coordenadas no sistema origem; $\vec{P}_{t_{k}}$ é o vetor dos parâmetros de transformação na época de sua determinação; $\vec{P}_{t_{k}}$ é o vetor das taxas de variação dos parâmetros na época de sua determinação; $\dot{T}_{X}, \dot{T}_{Y}, \dot{T}_{Z}, \dot{D}, \dot{R}_{X}, \dot{R}_{Y}$ e $\dot{R}_{Z}$ correspondem as taxas de variação anual dos parâmetros anteriormente descritos.

Posteriormente, os parâmetros atualizados são aplicados ao modelo matemático descrito na Eq. (1) para a compatibilização entre as materializações ITRF (IGS) de origem e destino. Salienta-se que tanto os parâmetros quanto as coordenadas consideradas nas materializações devem estar em uma mesma época $t_{o}$ (PETTIT; LUZUM, 2010).

Para algumas situações, as coordenadas compatibilizadas para o referencial de destino com época $\left(t_{o}\right)$ podem não ser suficientes, justificável pela incompatibilidade entre a época $t_{o}$ e a época de interesse $(t)$. Nesse caso, as coordenadas podem ser atualizadas ou reduzidas da época $t_{o}$ para uma época $t$ de interesse, utilizandose a Eq. (3) (CARVALHO, 2015; SIRGAS, 2020):

$$
\left[\begin{array}{l}
X \\
Y \\
Z
\end{array}\right]_{d(t)}=\left[\begin{array}{l}
X \\
Y \\
Z
\end{array}\right]_{d\left(t_{o}\right)}+\left[\begin{array}{l}
V_{X} \\
V_{Y} \\
V_{Z}
\end{array}\right]_{d}\left(t-t_{o}\right)
$$

em que $[X, Y, Z]_{d(t)}^{T}$ são as coordenadas da estação na época e referencial de interesse; $[X, Y, Z]_{d\left(t_{o}\right)}^{T}$ são as coordenadas cartesianas da estação na época de origem e referencial de interesse; $\left[V_{X}, V_{Y}, V_{Z}\right]_{d}^{T}$ são os vetores velocidade do ponto considerado no mesmo referencial das coordenadas na época $t_{o}$.

As componentes de velocidade utilizadas neste procedimento podem ser determinadas com algum modelo de velocidades ou deformações. No Brasil, por estar localizado na região de cobertura do SIRGAS, frequentemente utiliza-se o VEMOS2009 (Modelo de Velocidade para o SIRGAS, versão 2009) (DREWES; HEIDBACH, 2012). Salienta-se que este modelo é utilizado pelo IBGE-PPP para redução das coordenadas SIRGAS2000, da época de coleta dos dados para a época de referência - 2000,4 (IBGE, 2017).

Considerando que a interpretação de resultados associados às componentes cartesianas geocêntricas $X, Y$ e $Z$ é complexa, Leick (2004) destaca que tais resultados podem ser mais facilmente interpretados quando associados ao SGL (Sistema Geodésico Local). Além disso, Monico (2008) destaca que o SGL possibilita avaliar as variações locais específicas, ocorridas em $X, Y$ e $Z$, em termos das componentes horizontais e vertical.

$O$ relacionamento entre as componentes cartesianas geocêntricas $X, Y$ e $Z$ com as componentes norte, leste e vertical $(\Delta n, \Delta e, \Delta u)$ do SGL (Sistema Geodésico Local) é estabelecido por uma transformação específica, em que a origem e a orientação espacial do SGL são dependentes das componentes elipsoidais $\varphi_{o}$ (latitude) e $\lambda_{o}$ (longitude) do ponto de origem (LEICK, 2004; HOFMANN-WELLENHOF; LICHTENEGGER; WASLE, 2008). No caso das séries temporais o ponto de origem coincide com as componentes elipsoidais médias, ou seja, $\left(\varphi_{o}, \lambda_{o}\right)=(\bar{\varphi}, \bar{\lambda})$ (SILVA; MONICO, 2012; MACIUK; SZOMBARA, 2018). Nesse contexto, as séries temporais de componentes geodésicas locais $(\Delta n, \Delta e, \Delta u)$ são determinadas com a aplicação da Eq. (4) (LEICK, 2004): 


$$
\left[\begin{array}{l}
\Delta n_{j} \\
\Delta e_{j} \\
\Delta u_{j}
\end{array}\right]=\left[\begin{array}{ccc}
-\operatorname{sen} \bar{\varphi} \cos \bar{\lambda} & -\operatorname{sen} \bar{\varphi} \operatorname{sen} \bar{\lambda} & \cos \bar{\varphi} \\
-\operatorname{sen} \bar{\lambda} & \cos \bar{\varphi} & 0 \\
\cos \bar{\varphi} \cos \bar{\lambda} & \cos \bar{\varphi} \operatorname{sen} \bar{\lambda} & \operatorname{sen} \bar{\varphi}
\end{array}\right] *\left[\begin{array}{c}
X_{j}-\bar{X} \\
Y_{j}-\bar{Y} \\
Z_{j}-\bar{Z}
\end{array}\right]
$$

em que: $\left(\Delta n_{j}, \Delta e_{j}, \Delta u_{j}\right)$ são as componentes geodésicas locais da $j$-ésima época de interesse; $\left(X_{j}, Y_{j}, Z_{j}\right)$ são as componentes cartesianas da $j$-ésima época de interesse; $(\bar{X}, \bar{Y}, \bar{Z})$ são as componentes cartesianas médias das séries temporais consideradas; e, $(\bar{\varphi}, \bar{\lambda})$ são as componentes elipsoidais médias referentes às componentes cartesianas médias das séries temporais consideradas.

\section{MATERIAIS E MÉTODOS}

Para a realização dos experimentos foram utilizados dados de duas estações da RBMC, localizadas em Coari - AM (AMCO) e Manaus - AM (NAUS), como mostrado na Figura 1.

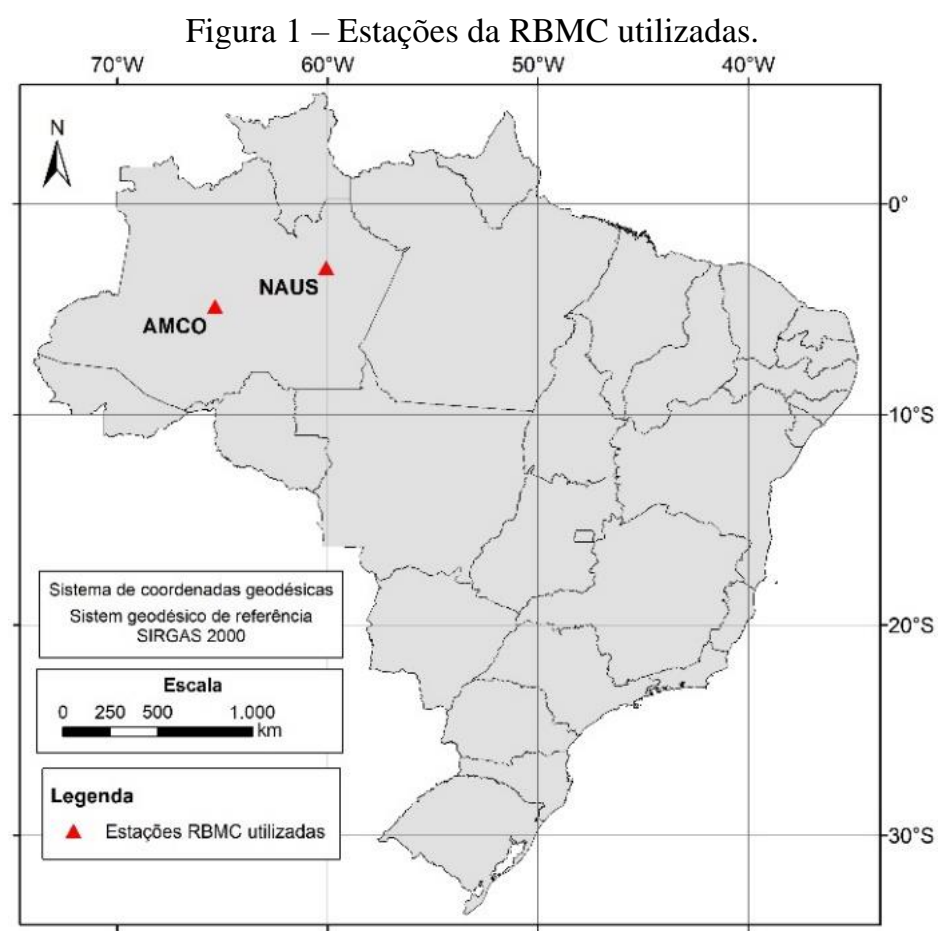

Fonte: Os autores (2021).

Os períodos considerados para as séries temporais posicionais são apresentados na Tabela 2, com suas respectivas estações.

Tabela 2 - Estações da RBMC utilizadas com os respectivos períodos considerados nas séries temporais. DOY (Dia do

\begin{tabular}{c|c|c|c}
\multicolumn{5}{|c}{$a n o)}$. \\
\hline Estações RBMC & Município & Data inicial & Data final \\
AMCO & Coari (AM) & $12 / 09 / 2012\left(\mathrm{DOY} \mathrm{n}^{\circ} 256\right)$ & \multirow{2}{*}{$31 / 12 / 2019\left(\mathrm{DOY} \mathrm{n}^{\circ} 365\right)$} \\
NAUS & Manaus (AM) & $01 / 01 / 2010\left(\mathrm{DOY} \mathrm{n}^{\circ} 001\right)$ & \\
\hline
\end{tabular}

Fonte: Os autores (2021).

Após a definição dos períodos considerados, realizou-se a geração das séries temporais posicionais utilizando o RINEX EDITION. Nesse caso, adquiriu-se arquivos de observações GNSS (GPS e GLONASS) em formato RINEX (Receiver Independent Exchange Format), com janelas de rastreio de 24 horas, que foram posteriormente enviados para processamento no IBGE-PPP, em modo estático. Salienta-se que o IBGE-PPP passou a adotar a integração GPS e GLONASS no processamento a partir de 14 de agosto de 2011 e, portanto, observações referentes a datas anteriores consideram somente a constelação GPS no processamento (IBGE, 2017). Apesar disso, Yigit et al. (2014), Ventorim e Dal Poz (2016) e Alcay e Yigit (2017) afirmam que a 
diferença entre os resultados do processamento de dados GNSS e somente GPS não é significativa (milimétrica) para a seção de rastreio utilizada.

Adicionalmente, destaca-se que o IBGE-PPP apresenta acurácia análoga ao Bernese GNSS Software (BSW) (versão 5.2) (FRIDEZ, 2019), se consideradas condições similares no processamento (método PPP em modo estático e arquivos GNSS com janela de rastreio de 24h) (OLIVEIRA; DAL POZ; ALMEIDA, 2019; BRAGA; DAL POZ, 2019).

De posse das séries temporais posicionais, observou-se que estas compreenderam pelo menos três materializações do ITRF (IGS). Portanto, efetuou-se a compatibilização dos referenciais das séries temporais para o SIRGAS2000 utilizando quatro estratégias, subdivididas em dois experimentos, descritos na sequência.

\subsection{Experimento 1}

Nesse experimento, a compatibilização entre as materializações do ITRF (IGS) e SIRGAS2000 foi efetuada seguindo a metodologia aplicada pelo IBGE-PPP (exceto a transformação para o SGL) apresentada na Figura 2.

Figura 2 - Fluxograma metodológico para compatibilização entre ITRF (IGS) e SIRGAS2000 nas séries temporais.

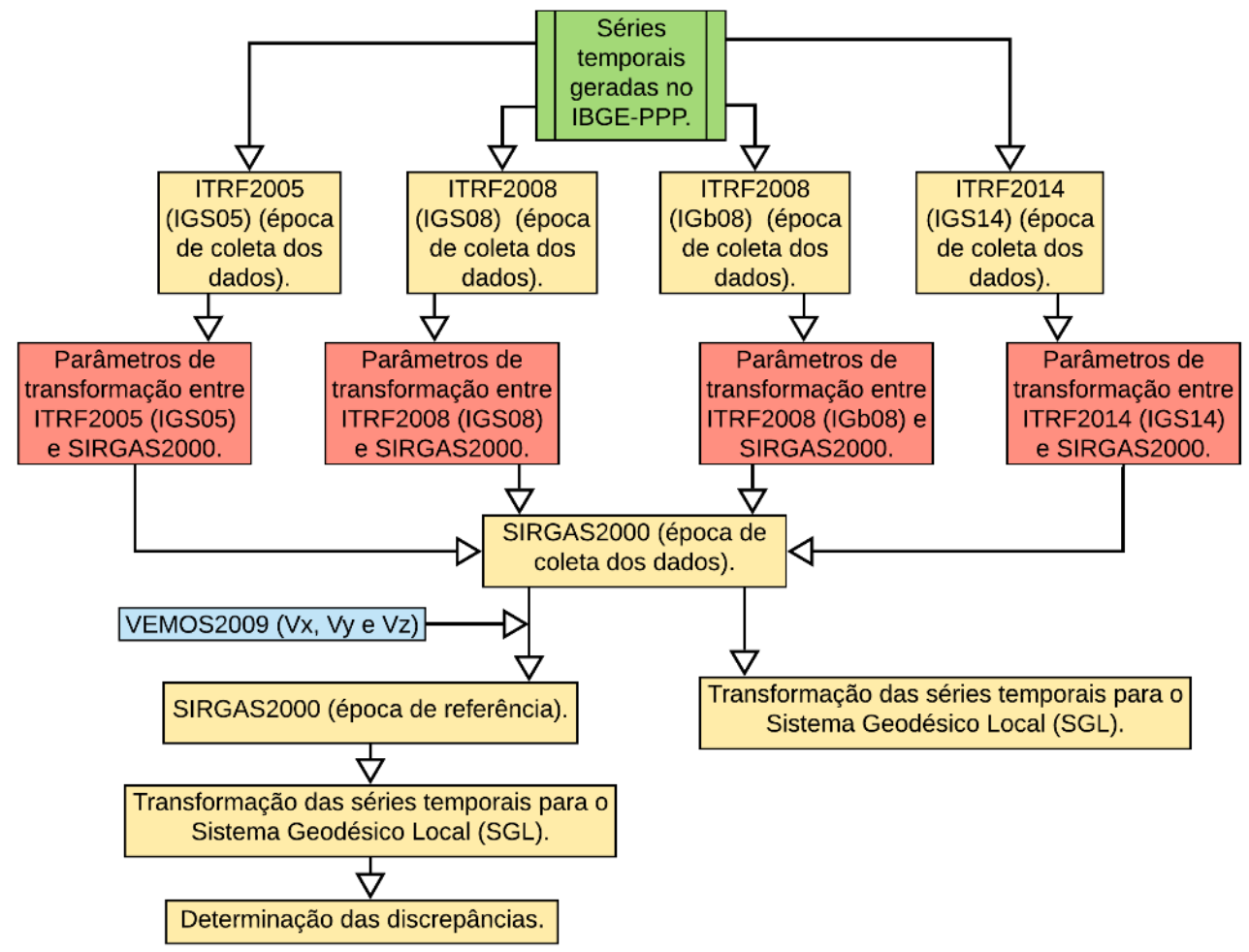

Fonte: Os autores (2021).

Nesta etapa, utilizou-se a transformação de Helmert (Eq. 1) juntamente com os dois conjuntos de parâmetros de transformação entre ITRF (IGS) e SIRGAS2000 disponibilizados pelo IBGE. O primeiro conjunto (P1) refere-se aos parâmetros utilizados pelo IBGE-PPP anteriormente a 17 de maio de 2020, apresentados na Tabela 3 .

Tabela 3 - Parâmetros de transformação entre ITRF (IGS) e SIRGAS2000, anteriores a 17/05/2020. *mas: milisegundo

\begin{tabular}{c|c|c|c|c|c|r|r}
\hline \multicolumn{1}{c}{ Parâmetros } & $\begin{array}{c}\boldsymbol{T}_{\boldsymbol{X}} \\
(\mathbf{m m})\end{array}$ & $\begin{array}{c}\boldsymbol{T}_{\boldsymbol{Y}} \\
(\mathbf{m m})\end{array}$ & $\begin{array}{c}\boldsymbol{T}_{\boldsymbol{Z}} \\
(\mathbf{m m})\end{array}$ & $\begin{array}{c}\boldsymbol{D} \\
(\mathbf{p p b})\end{array}$ & $\begin{array}{c}\boldsymbol{R}_{\boldsymbol{X}} \\
(\mathbf{m a s})\end{array}$ & $\begin{array}{c}\boldsymbol{R}_{\boldsymbol{Y}} \\
(\mathbf{m a s})\end{array}$ & $\begin{array}{c}\boldsymbol{R}_{\boldsymbol{Z}} \\
(\mathbf{m a s})\end{array}$ \\
\hline ITRF2005 (IGS05) para SIRGAS2000 & 5,1 & 6,5 & 9,9 & 0,00 & $-0,150$ & 0,020 & 0,021 \\
ITRF2008 (IGS08) para SIRGAS2000 & 2,5 & 4,3 & 4,6 & $-1,10$ & 0,140 & $-0,010$ & 0,080 \\
ITRF2008 (IGb08) para SIRGAS2000 & 2,0 & 4,1 & 3,9 & $-1,00$ & 0,170 & $-0,030$ & 0,070 \\
ITRF2014 (IGS14) para SIRGAS2000 & 2,6 & 1,8 & $-6,1$ & $-0,05$ & 0,308 & 0,106 & $-0,096$ \\
\hline
\end{tabular}

Fonte: IBGE (2017). 
O segundo conjunto de parâmetros (P2), mostrados na Tabela 4, começaram a ser utilizados pelo IBGE-PPP a partir de 17 de maio de 2020. IBGE-PPP (2020) ressalta que P2 foi instituído no sentido de diminuir os impactos causados pelas trocas de referenciais ocorridas ao longo do tempo.

Tabela 4 - Parâmetros de transformação entre ITRF (IGS) e SIRGAS2000, a partir de 17/05/2020. *mas: milisegundo

\begin{tabular}{c|c|c|c|c|c|c|c}
\hline Parâmetros & $\begin{array}{c}\boldsymbol{T}_{\boldsymbol{X}} \\
(\mathbf{m m})\end{array}$ & $\begin{array}{c}\boldsymbol{T}_{\boldsymbol{Y}} \\
(\mathbf{m m})\end{array}$ & $\begin{array}{c}\boldsymbol{T}_{\boldsymbol{Z}} \\
(\mathbf{m m})\end{array}$ & $\begin{array}{c}\boldsymbol{D} \\
(\mathbf{p p b})\end{array}$ & $\begin{array}{c}\boldsymbol{R}_{\boldsymbol{X}} \\
(\mathbf{m a s})\end{array}$ & $\begin{array}{c}\boldsymbol{R}_{\boldsymbol{Y}} \\
(\mathbf{m a s})\end{array}$ & $\begin{array}{c}\boldsymbol{R}_{\boldsymbol{Z}} \\
(\mathbf{m a s})\end{array}$ \\
\hline ITRF2005 (IGS05) para SIRGAS2000 & $-0,8$ & $-3,9$ & $-6,1$ & $-0,18$ & 0,000 & 0,000 & 0,000 \\
ITRF2008 (IGS08) para SIRGAS2000 & $-3,4$ & $-4,8$ & $-8,6$ & 1,62 & 0,000 & 0,000 & 0,000 \\
ITRF2008 (IGb08) para SIRGAS2000 & $-3,4$ & $-5,4$ & $-8,8$ & 1,57 & 0,000 & 0,000 & 0,000 \\
ITRF2014 (IGS14) para SIRGAS2000 & $-2,6$ & $-3,2$ & $-4,2$ & 1,22 & 0,000 & 0,000 & 0,000 \\
\hline
\end{tabular}

Fonte: IBGE (2020).

Vale ressaltar que o IBGE não disponibiliza as variações temporais dos parâmetros e, portanto, não há necessidade de atualiza-los para a época das coordenadas.

Posteriormente, as séries em SIRGAS2000, obtidas com o IBGE-PPP na época dos dados, foram transformadas para o SGL aplicando-se a Eq. (4). Adicionalmente, reduziu-se tais séries em SIRGAS2000 para a época de referência $(2000,4)$ aplicando-se a Eq. (3), utilizando as componentes de velocidades extraídas do VEMOS2009 (Modelo de Velocidade para o SIRGAS 2009) (DREWES; HEIDBACH, 2012). Na sequência, transformou-se tanto as componentes posicionais das séries reduzidas, quanto as componentes obtidas nos descritivos das estações da RBMC, também referenciadas ao SIRGA2000, época 2000,4, para o SGL conforme Eq. (4). Nesse caso, considerou-se como origem do SGL as coordenadas médias das séries reduzidas e dos descritivos, respectivamente. Por fim, determinou-se as discrepâncias planimétrica e altimétrica a partir das componentes do SGL, utilizando como referência as componentes oriundas dos referidos descritivos das estações.

\subsection{Experimento 2}

O segundo experimento consistiu na compatibilização das materializações ITRF (IGS) das séries temporais para o ITRF2014 (IGS14) (materialização mais consistente). Deste, as séries foram compatibilizadas para o SIRGAS2000 utilizando P1 e P2. A sequência metodológica aplicada é descrita na Figura 3. 
Figura 3 - Fluxograma metodológico para compatibilização das materializações ITRF (IGS) para o ITRF2014 (IGS14) e deste para SIRGAS2000 nas séries temporais.

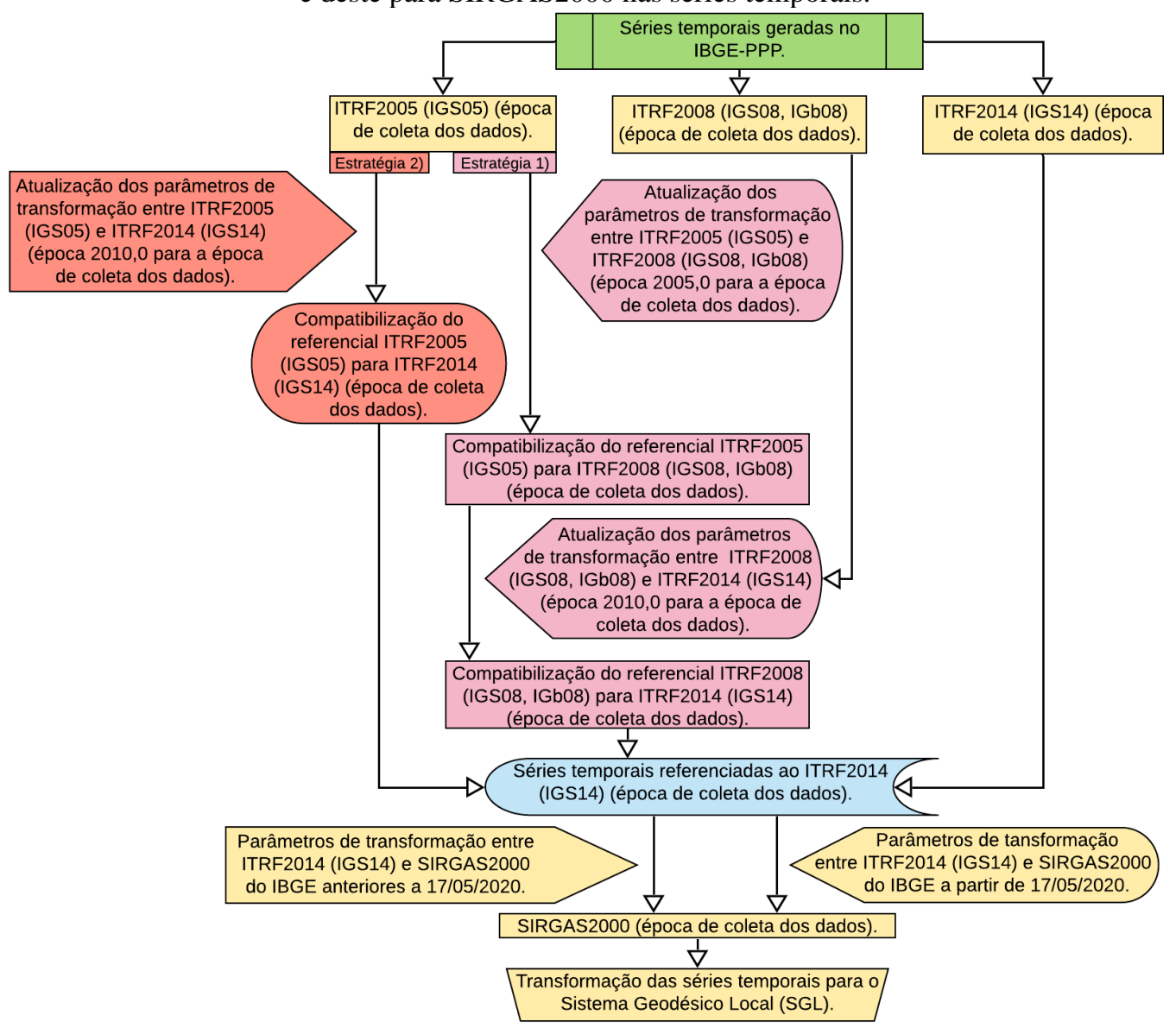

Fonte: Os autores (2021).

Neste procedimento os conjuntos de parâmetros de transformação, apresentados na Tabela 5, foram inicialmente atualizados para as épocas das coordenadas utilizando a Eq. 2 e, em seguida, aplicados na transformação de Helmert (Eq. 1) para a compatibilização das séries para o ITRF2014 (IGS14).

Tabela 5 - Parâmetros de transformação entre as materializações dos ITRF (IGS). *mas: milisegundo de arco.

\begin{tabular}{|c|c|c|c|c|c|c|c|}
\hline Parâmetros & $\begin{array}{c}T_{X} \\
(\mathbf{m m})\end{array}$ & $\begin{array}{c}T_{Y} \\
(\mathrm{~mm})\end{array}$ & $\begin{array}{c}T_{Z} \\
(\mathrm{~mm})\end{array}$ & $\begin{array}{c}D \\
(\mathbf{p p b})\end{array}$ & $\begin{array}{c}R_{X} \\
(\mathrm{mas})\end{array}$ & $\begin{array}{c}R_{Y} \\
(\mathrm{mas})\end{array}$ & $\begin{array}{c}R_{Z} \\
\text { (mas) }\end{array}$ \\
\hline ITRF2014 para ITRF2008, época 2010,0 & 1,6 & 1,9 & 2,4 & $-0,02$ & 0,000 & 0,000 & 0,000 \\
\hline ITRF2008 para ITRF2005, época 2005,0 & $-0,5$ & $-0,9$ & $-4,7$ & 0,94 & 0,000 & 0,000 & 0,000 \\
\hline ITRF2014 para ITRF2005, época 2010,0 & 2,6 & 1,0 & $-2,3$ & 0,92 & 0,000 & 0,000 & 0,000 \\
\hline Variações temporais (rates) & $\begin{array}{c}\dot{T}_{X} \\
(\mathbf{m m} \\
\text { /ano) }\end{array}$ & $\begin{array}{c}\dot{T}_{Y} \\
(\mathbf{m m} \\
\text { /ano) }\end{array}$ & $\begin{array}{c}\dot{T}_{Z} \\
(\mathbf{m m} \\
\text { /ano) }\end{array}$ & $\begin{array}{c}\dot{D} \\
(\mathbf{p p b} \\
\text { /ano) }\end{array}$ & $\begin{array}{c}\dot{\boldsymbol{R}}_{\boldsymbol{X}} \\
\text { (mas } \\
\text { /ano) }\end{array}$ & $\begin{array}{c}\dot{R}_{Y} \\
\text { (mas } \\
\text { /ano) }\end{array}$ & $\begin{array}{c}\dot{R}_{Z} \\
\text { (mas } \\
\text { /ano) } \\
\end{array}$ \\
\hline ITRF2014 para ITRF2008, época 2010,0 & 0,0 & 0,0 & $-0,1$ & 0,03 & 0,000 & 0,000 & 0,000 \\
\hline ITRF2008 para ITRF2005, época 2005,0 & 0,3 & 0,0 & 0,0 & 0,00 & 0,000 & 0,000 & 0,000 \\
\hline ITRF2014 para ITRF2005, época 2010,0 & 0,3 & 0,0 & $-0,1$ & 0,03 & 0,000 & 0,000 & 0,000 \\
\hline
\end{tabular}

Fonte: Petit e Luzum (2010); Altamimi, Collilieux e Métivier (2012) e Altamimi et al. (2016).

Considerando a compatibilização entre o ITRF2005 (IGS05) e ITRF2014 (IGS14), utilizou-se duas estratégias distintas: 1) de ITRF2005 (IGS05) para ITRF2008 (IGS08) e deste para ITRF2014 (IGS14) (forma intermediária); 2) de ITRF2005 (IGS05) para ITRF2014 (IGS14) (forma direta). O ITRF2008 (IGS08, IGb08) foi diretamente compatibilizado para o ITRF2014 (IGS14). Destaca-se que a forma intermediária de compatibilização entre ITRF2005 (IGS05) e ITRF2014 (IGS14) detém maior rigor teórico, conforme evidenciado por Carvalho (2015), Ramos, Dal Poz e Carvalho (2016), Braga e Dal Poz (2017) dentre outros.

$\mathrm{Na}$ sequência, as séries temporais posicionais referenciadas ao ITRF2014 (IGS14) foram compatibilizadas para o SIRGAS2000 aplicando-se a Eq. 1 com os conjuntos de parâmetros de transformação 
entre ITRF2014 (IGS14) e SIRGAS2000 apresentados nas Tabelas 3 e 4. Posteriormente, as séries referenciadas ao ITRF2014 (IGS14) e ao SIRGAS2000 foram transformadas para o SGL aplicando-se a Eq. 4.

Salienta-se que todos os procedimentos inerentes ao desenvolvimento metodológico, bem como os gráficos gerados, foram implementados em scripts no software R (R CORE TEAM, 2020).

\section{RESULTADOS E DISCUSSÕES}

Com a finalidade de melhorar a visualização e tornar as análises mais claras e consistentes, destacouse nas figuras os períodos referentes às épocas de cada materialização do ITRF (IGS), bem como as épocas de trocas de antenas, receptores e conjunto de antena e receptor. Os sinais + ou - associados aos valores das mudanças de nível indicam o sentido (acima ou abaixo) destas em relação às séries SIRGAS2000 compatibilizado com P2. Entenda-se por mudanças de nível as variações ocorridas entre as séries SIRGAS2000 compatibilizado com P2 e SIRGAS2000 compatibilizado com P1, considerando um mesmo período de tempo.

\subsection{Experimento 1}

Analisando as séries temporais referenciadas ao SIRGAS2000 compatibilizado com P1(SCP1), podese observar que estas apresentam diferenças quando comparadas às séries SIRGAS2000 compatibilizadas com P2 (SCP2), como mostrado na Figura 4. Diferenças significativas foram apresentadas nas séries de componentes norte $(\Delta n)$ e estão relacionadas à períodos específicos. De fato, a série $\Delta n$ SCP1 da estação NAUS apresenta duas mudanças de nível de aproximadamente $\pm 0,017 \mathrm{~m}$ em relação à série SCP2. Tais mudanças de nível associam-se aos períodos referentes às materializações do ITRF2005 (IGS05) e ITRF2014 (IGS14). Analogamente, a série $\Delta n$ SCP1 da estação AMCO possui uma mudança de nível de aproximadamente $-0,013$ m quando comparada a SCP2, referente à materialização do ITRF2014 (IGS14). Mudança de nível entre as séries $\Delta n$ SCP1 e SCP2 das estações NAUS e AMCO podem ser verificadas para os períodos referentes às materializações do ITRF2008 (IGS08) e ITRF2008(IGb08), com magnitudes menores, variando entre $+0,003$ $\mathrm{m} \mathrm{e}+0,006 \mathrm{~m}$.

As séries de componentes leste $(\Delta e) \mathrm{SCP} 1$ também apresentaram diferenças quando comparadas à SPC2, porém com magnitudes menores nas mudanças de nível, variando entre $+0,001 \mathrm{~m} \mathrm{e}-0,006 \mathrm{~m} \mathrm{e}+0,002$ $\mathrm{m}$ e $-0,005 \mathrm{~m}$ para as estações NAUS e AMCO, respectivamente. As maiores variações ocorreram no período da materialização do ITRF2014 (IGS14).

Comparando as séries de componentes vertical $(\Delta u)$ SCP1 e SCP2, constatou-se mudanças de nível com variações entre $+0,007 \mathrm{~m}$ e $+0,012 \mathrm{~m}$ e $-0,004 \mathrm{~m} \mathrm{e}+0,009 \mathrm{~m}$ para as estações NAUS e AMCO, respectivamente. Os maiores valores das variações ocorreram no período das materializações do ITRF2005 (IGS05) e ITRF2014 (IGS14) para as estações NAUS e AMCO, nesta ordem.

Adicionalmente, salienta-se que mudanças de nível ocasionadas por fatores artificiais (trocas de antenas, receptores ou conjunto de antena e receptor) foram verificadas nas séries da estação NAUS. 
Figura 4 - Séries de componentes do SGL referenciadas ao SIRGAS2000 compatibilizado com P1 (azul) e P2 (colorida). As linhas verticais correspondem à época de troca de antena (azul), troca de receptor (verde) e troca do conjunto de antena e receptor (vermelha).
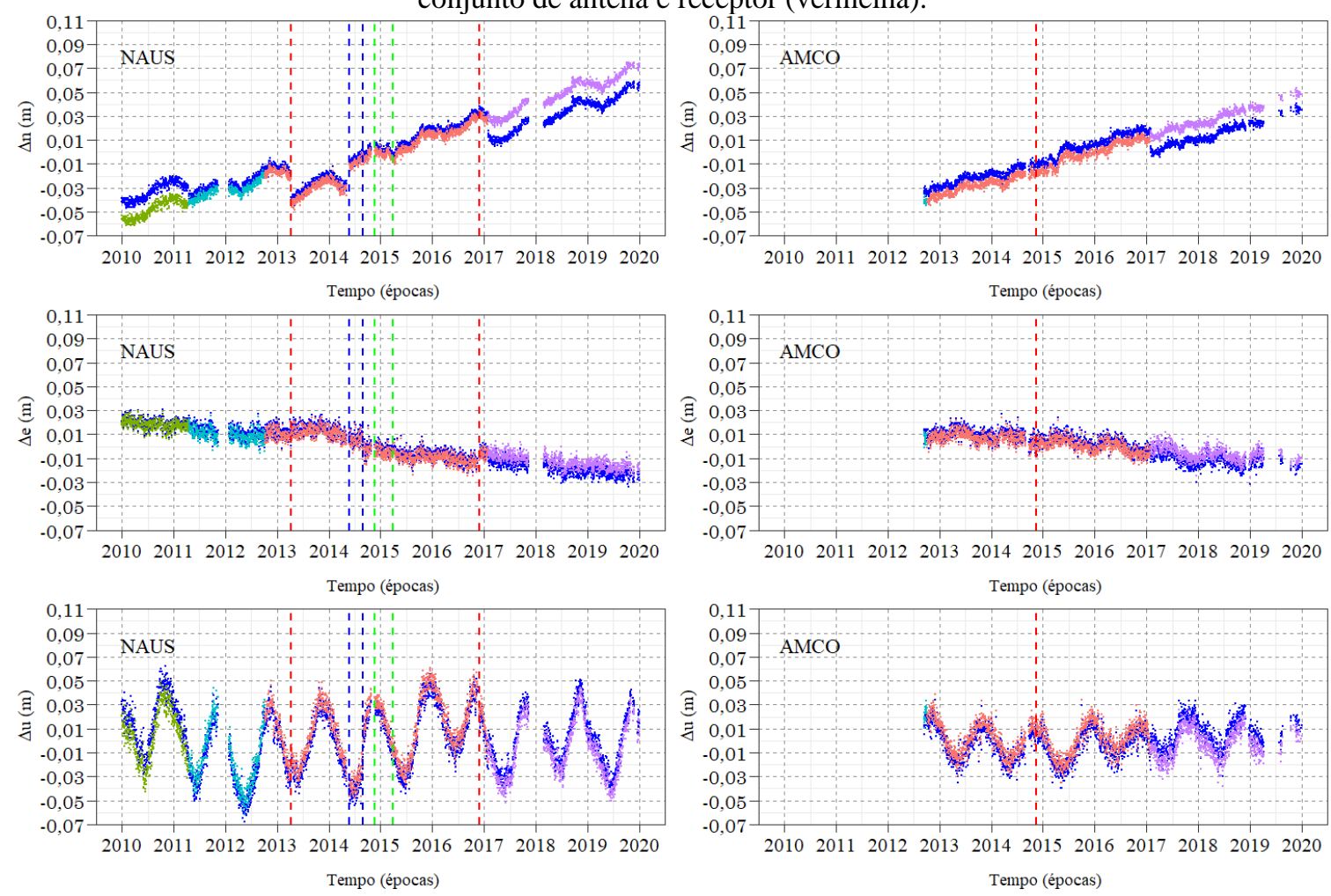

SISTEMAS DE REFERÊNCIA ORIGINAIS

ITRF2005(IGS05) ITRF2008(IGS08) ITRF2008(IGb08) ITRF2014(IGS14)

Fonte: Os autores (2021).

Dessa forma, pode-se observar que mesmo com as diferenças entre P1 e P2 as soluções obtidas apresentaram uma pequena alteração nas mudanças de nível (milimétricas) para os períodos referentes às materializações do ITRF2008 (IGS08) e ITRF2008(IGb08), quando comparadas às mudanças de nível associados às materializações do ITRF2005 (IGS05) e ITRF2014(IGS14) (centimétricas), para algumas das componentes. Tal fato pode ser justificado, dentre outros fatores, pelo acréscimo gradativo no número de estações de referência utilizadas na evolução das materializações/realizações dos ITRF (IGS), quanto pela consideração de movimentos não lineares das estações, que incluiu sinais sazonais (anuais e semestrais) de posições de estações e deformações ocorridas após eventos sísmicos causados por grandes terremotos, caso do ITRF2014(IGS14).

De fato, IBGE-PPP (2020) destaca que a utilização dos parâmetros P2 pode gerar diferenças, cuja magnitude pode variar de poucos milímetros a até $0,02 \mathrm{~m}$ na componente planimétrica e de alguns milímetros a até $0,03 \mathrm{~m}$, quando comparadas com as coordenadas determinadas com os parâmetros antigos - P1. Desse modo, os resultados encontrados se enquadram no intervalo estipulado, para ambas as estações, tanto na componente planimétrica quanto na altimétrica. Nesse âmbito, as variações verificadas nas componentes posicionais podem comprometer o processo de atualização/integração de produtos geodésicos/cartográficos associados às coordenadas SIRGAS2000 determinadas com P1 (levantamento antigo) e P2 (levantamento recente).

Ademais, verificou-se que algumas das componentes foram mais afetadas do que outras, o que pode ser justificado pela influência da dinâmica das deformações da crosta terrestre ocorridas em resposta ao efeito da carga hidrológica recorrente na bacia Amazônica, principalmente em locais próximos à grandes corpos d'água, regiões de remanso e zonas úmidas, como Manaus, onde está localizada a estação NAUS. Nesse caso, o comportamento das deformações nas componentes posicionais das estações é dependente da sua localização e deve ser investigado.

Considerando as séries das discrepâncias referentes a SCP1 e SCP2, dispostas na Figura 5, observa-se que as séries de discrepâncias planimétricas SCP1 e SCP2 referentes à estação NAUS apresentaram mudanças 
de nível de aproximadamente $+0,017 \mathrm{~m},+0,014 \mathrm{~m},+0,012 \mathrm{~m}$ e $+0,002 \mathrm{~m}$ referente ao período das materializações do ITRF2005 (IGS05), ITRF2008 (IGS08), ITRF2008(IGb08) e ITRF2014 (IGS14), respectivamente. As séries de discrepâncias planimétricas SCP1 e SCP2 para AMCO apresentaram comportamento distinto da NAUS, denotando mudanças de nível de aproximadamente $+0,009$ m no período das materializações do ITRF2005 (IGS05), ITRF2008 (IGS08) e ITRF2008(IGb08) e -0,012 m para o ITRF2014 (IGS14), respectivamente.

Quanto às séries das discrepâncias altimétricas SCP1 e SCP2, apresentadas na Figura 5, observa-se que a estação NAUS apresentou mudanças de nível de aproximadamente $-0,005 \mathrm{~m},-0,022 \mathrm{~m},-0,022 \mathrm{~m}$ e $-0,009$ m para o período das materializações do ITRF2005 (IGS05), ITRF2008 (IGS08), ITRF2008(IGb08) e ITRF2014 (IGS14), respectivamente. Mudanças de nível de aproximadamente $-0,023 \mathrm{~m} \mathrm{e}-0,010 \mathrm{~m}$ foram observadas nas séries das discrepâncias altimétricas SCP1 e SCP2 da estação AMCO, para o período das materializações do ITRF2008 (IGS08 e IGb08) e ITRF2014(IGS14).

Figura 5 - Séries de discrepâncias planimétricas e altimétricas referentes às séries referenciadas ao SIRGAS2000 compatibilizado com P1 (azul) e P2 (colorida), reduzidas à época de referência 2000,4. As linhas verticais correspondem a época de troca de antena (azul), troca de receptor (verde) e troca do conjunto de antena e receptor (vermelha).
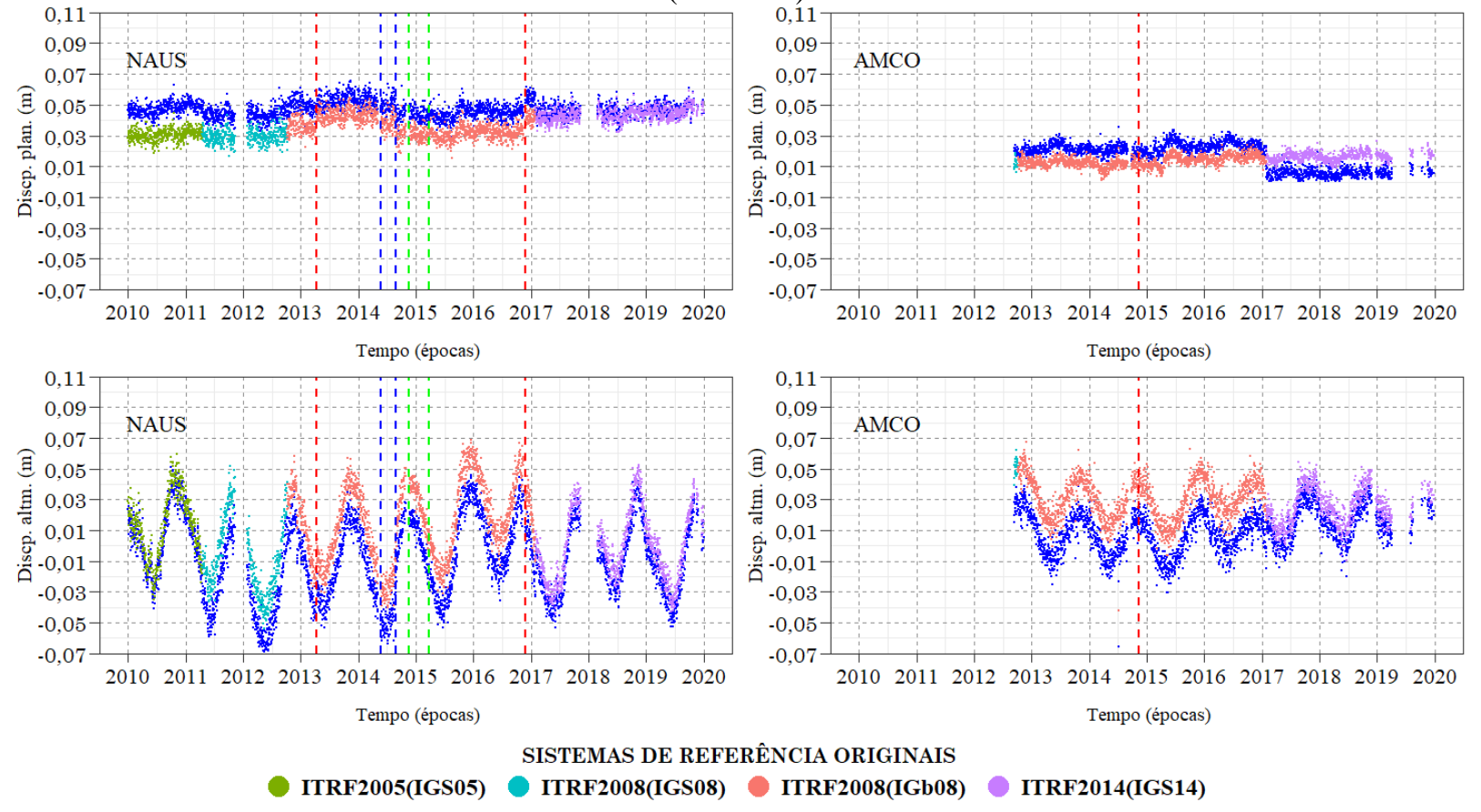

SISTEMAS DE REFERÊNCIA ORIGINAIS

ITRF2005(IGS05) ITRF2008(IGS08) ITRF2008(IGb08) ITRF2014(IGS14)

Fonte: Os autores (2021).

Considerando as séries de discrepâncias planimétricas individualmente, observa-se que a série SCP1 da estação NAUS possui maior estabilidade, o que também se observa para a série SCP2 da estação AMCO. Dessa forma, estudos que se fundamentem em tais discrepâncias podem ter seus resultados sub ou superestimado a depender da época, ou conjunto de épocas, consideradas.

\subsection{Experimento 2}

As séries SCP2 obtiveram resultados similares às séries compatibilizadas para o ITRF2014(IGS14) para as estações NAUS e AMCO, como apresentados na Figura 6. Diferenças milimétricas $(\sim 0,002 \mathrm{~m})$ foram obtidas no período referente à materialização do ITRF2005 (IGS05) e do ITRF2014 (IGS14) para a estação NAUS. Nos demais períodos, as diferenças obtiveram ordem menores ou iguais à sub milimétrica $\left(\leq 10^{-4} \mathrm{~m}\right)$, para ambas estações. 
Figura 6 - Séries de componentes do SGL referentes às séries referenciadas ao SIRGAS2000 compatibilizado com P2 (colorida) e ITRF2014 (azul). As linhas verticais correspondem a época de troca de antena (azul), troca de receptor (verde) e troca do conjunto de antena e receptor (vermelha).
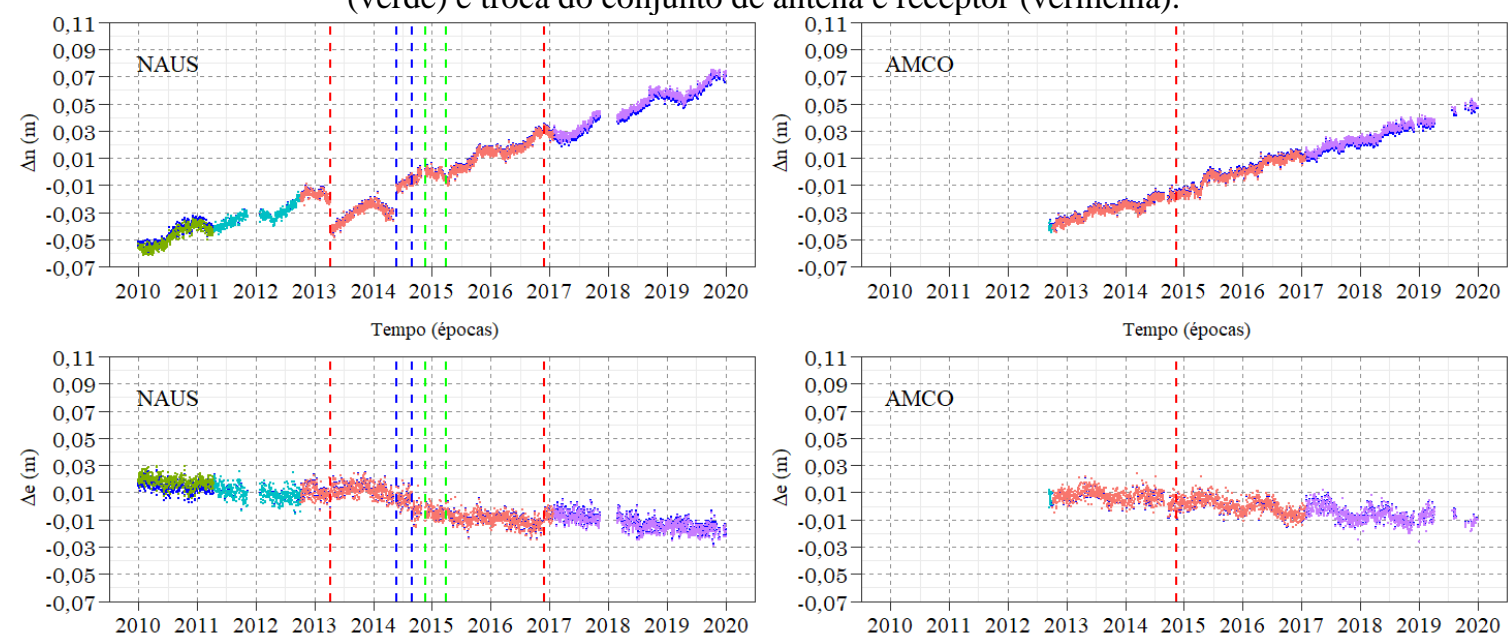

Tempo (épocas)
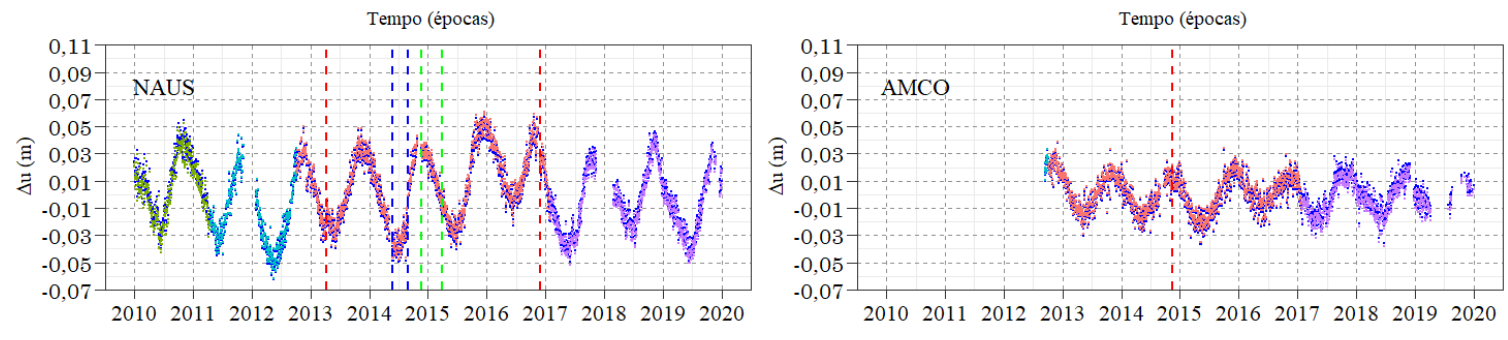

SISTEMAS DE REFERÊNCIA ORIGINAIS

ITRF2005(IGS05) ITRF2008(IGS08) ITRF2008(IGb08) ITRF2014(IGS14)

Fonte: Os autores (2021).

Após a compatibilização das séries do ITRF2014 (IGS14) para o SIRGAS2000, com P1 (ITSP1) e P2 (ITSP2), observou-se que estas não apresentaram diferenças significativas (da ordem de $10^{-11} \mathrm{~m}$ ), como se pode observar na Figura 7. 
Figura 7 - Séries de componentes do SGL referenciadas ao SIRGAS2000 compatibilizado do ITRF2014 (IGS14) com P2 (colorida) e SIRGAS2000 compatibilizado do ITRF2014 (IGS14) com P1 (azul). As linhas verticais correspondem à época de troca de antena (azul), troca de receptor (verde) e troca do conjunto de antena e receptor (vermelha).
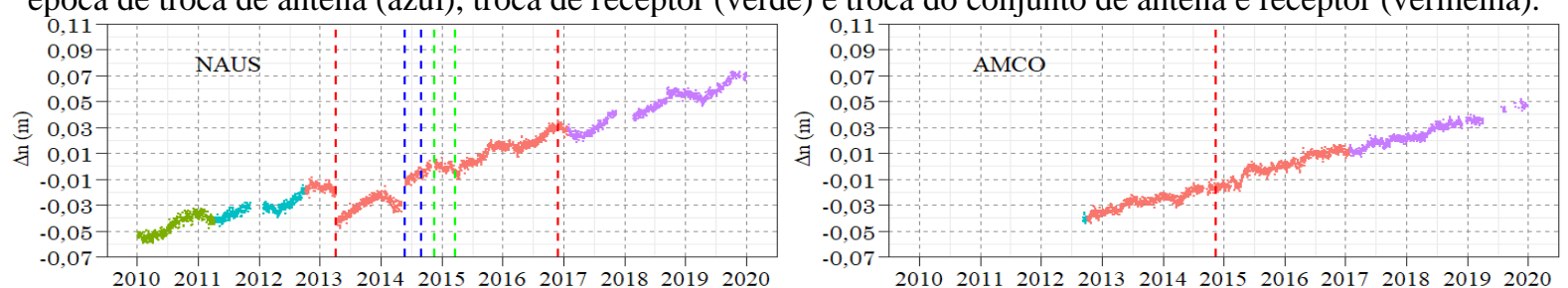

Tempo (épocas)
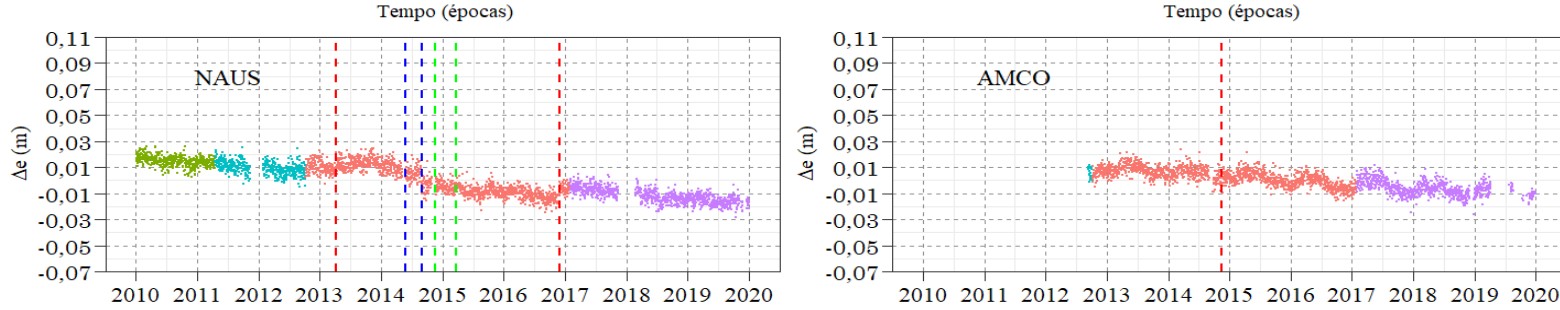

Tempo (épocas)
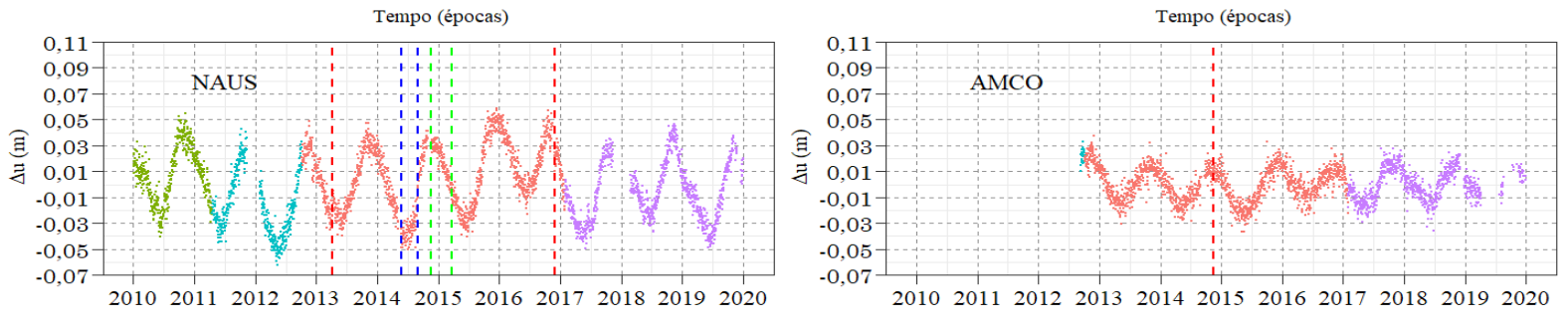

Tempo (épocas) Tempo (épocas)

SISTEMAS DE REFERENNCIA ORIGINAIS

(IGS05) (IGS08) (IGb08) (IGS14)

Fonte: Os autores (2021).

Figura 8 - Séries de componentes do SGL referenciadas ao SIRGAS2000 compatibilizado com P2 (colorida) e SIRGAS2000 compatibilizado do ITRF2014 (IGS14) com P2 (azul). As linhas verticais correspondem à época de troca de antena (azul), troca de receptor (verde) e troca do conjunto de antena e receptor (vermelha).
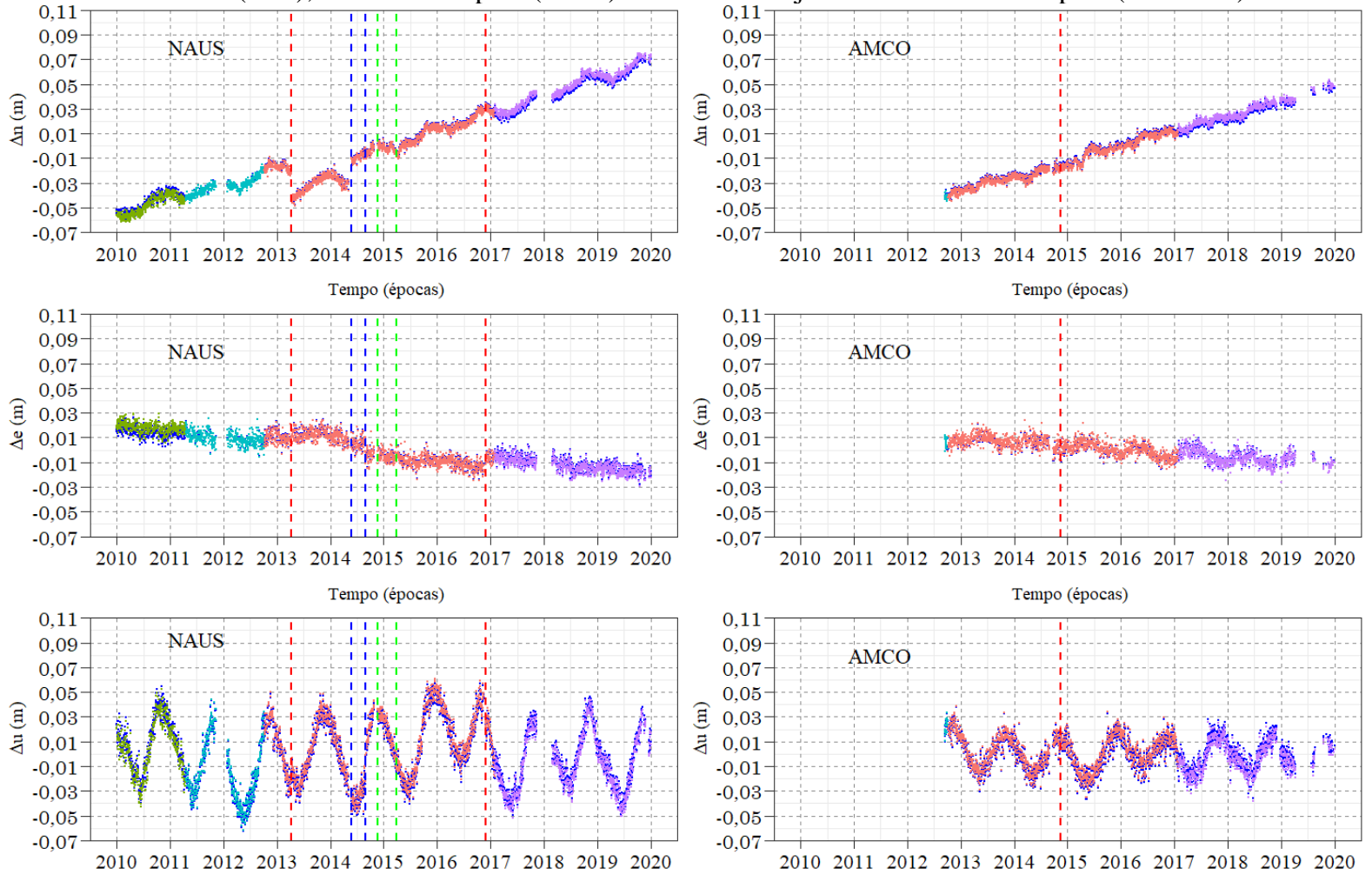

Tempo (épocas)

Tempo (épocas)

SISTEMAS DE REFERÊNCIA ORIGINAIS

ITRF2005(IGS05) ITRF2008(IGS08) ITRF2008(IGb08) ITRF2014(IGS14)

Fonte: Os autores (2021). 
Nesse sentido, quando comparadas as séries SCP2 com as séries ITSP2, dispostas na Figura 8, podese constatar que estas apresentaram resultados similares aos observados na comparação entre as séries SCP2 e ITRF2014 (IGS14), apresentadas na Figura 6. Resultados idênticos foram encontrados na comparação das séries SCP2 com as séries ITSP1.

\section{CONCLUSÕES}

Considerando os conjuntos de parâmetros de transformação entre as materializações ITRF (IGS) e SIRGAS2000, pode-se observar que as séries SCP2 apresentaram resultados mais consistentes quando comparadas às séries SCP1. De fato, tal comportamento ressalta que P2 foi instituído no sentido de diminuir os impactos causados pelas trocas de referenciais ocorridas ao longo do tempo, o que foi claramente demonstrado neste trabalho.

Dentre as séries SCP1, as das componentes $\Delta n$ foram mais afetadas obtendo maior magnitude nas mudanças de nível, tanto absolutas, quanto relativas às séries $\mathrm{SCP} 2$ nos períodos referentes às materializações do ITRF2005 (IGS05) e ITRF2014 (IGS14). As séries SCP1 das componentes $\Delta e$ e $\Delta u$ também apresentaram mudanças de nível quando comparadas às séries SCP2, porém com menor magnitude. Adicionalmente, salienta-se que mudanças de nível ocasionadas por fatores artificiais (trocas de antenas, receptores ou conjunto de antena e receptor) foram verificadas nas séries da estação NAUS.

Quanto às séries das discrepâncias referentes a SCP1 e SCP2, verificou-se que estas também apresentaram divergências. Observou-se que as séries de discrepâncias planimétricas SCP1 e SCP2 da estação NAUS exibiram diferenças decrescentes, associadas à evolução temporal das materializações do ITRF (IGS).

Já na estação AMCO, um comportamento distinto foi verificado, com a maior mudança de nível associada ao ITRF2014 (IGS14). As séries das discrepâncias altimétricas SCP1 e SCP2 também apresentaram mudanças de nível, com menores magnitudes. No entanto, cabe destacar que as discrepâncias altimétricas refletem o comportamento das séries na época dos dados, uma vez que o modelo de velocidades utilizado proporciona somente a redução das coordenadas planimétricas (IBGE, 2015).

Na etapa de compatibilização das materializações do ITRF (IGS) para o ITRF2014 (IGS14), observouse que as duas estratégias utilizadas para a compatibilização do ITRF2005 (IGS05) apresentaram resultados similares. Nesse caso, a aplicação da segunda estratégia pode ser mais viável por ser direta, otimizando a implementação. Comparando as séries SCP2 com as séries em ITRF2014 (IGS), verificou-se que há compatibilidade entre as soluções SIRGAS2000 e ITRF2014 (IGS14) do IBGE-PPP ao nível menor ou igual a $0,002 \mathrm{~m}$ para as estações utilizadas. Nesse sentido, devido à consistência apresentada pelas séries SCP2, estas podem ser aplicadas diretamente em estudos associados às séries temporais posicionais referentes ao território brasileiro, uma vez que o SIRGAS2000 é o sistema de referência oficial brasileiro e deve ser adotado em todas as atividades de informações geoespaciais.

Considerando a compatibilização das séries em ITRF2014 (IGS14) para o SIRGAS2000 com P1 (ITSP1) ou P2 (ITSP2), verificou-se que a diferença entre ambas não foi significativa, da ordem de $10^{-11} \mathrm{~m}$. Ademais, os resultados obtidos na comparação entre as séries ITSP1/ITSP2 com a SCP2 foram similares aos encontrados na comparação entre as séries em ITRF2014 (IGS14) e SCP2.

Portanto, a compatibilização das materializações do ITRF (IGS) para o ITRF2014 (IGS14) e deste para o SIRGAS2000 com P1 ou P2 constitui uma opção para a obtenção de séries em SIRGAS2000, compatíveis com as séries em ITRF2014 (IGS14), ao nível menor ou igual ao milimétrico. No entanto, o procedimento de compatibilização das materializações do ITRF (IGS) para o ITRF2014 (IGS14) exige a realização de mais etapas, o que o torna menos viável em relação às séries SCP2 disponibilizadas diretamente pelo IBGE-PPP, a partir de 17 de maio de 2020.

\section{Agradecimentos}

Esta pesquisa teve o incentivo da Universidade Federal de Viçosa através do Departamento de Engenharia Civil, curso de Pós-Graduação em Engenharia Civil. O presente trabalho foi realizado com apoio da Coordenação de Aperfeiçoamento de Pessoal de Nível Superior -Brasil (CAPES) - Código de 
Financiamento 001. Agradecimentos ao Instituto Federal do Norte de Minas (IFNMG) pela licença concedida para cursar pós-graduação e ao Instituto Brasileiro de Geografia e Estatística (IBGE) pela disponibilidade dos dados referentes à Rede Brasileira de Monitoramento contínuo dos Sistemas GNSS (RBMC) e do serviço online IBGE-PPP (Instituto Brasileiro de Geografia e Estatística - PPP).

\section{Contribuição dos Autores}

O primeiro autor foi responsável pela Conceptualização, Curadoria dos dados, Análise formal, Investigação, Metodologia, Software, Visualização e Redação - minuta inicial. O segundo autor foi responsável pela Supervisão, Validação e Redação - revisão e edição. O terceiro autor foi responsável pela Curadoria dos dados, Software, Visualização e Redação - minuta inicial.

\section{Conflitos de Interesse}

Os autores declaram que não há conflitos de interesse.

\section{Referências}

ALCAY, S.; YIGIT, C. O. Network based performance of GPS-only and combined GPS/GLONASS positioning under different sky view conditions. Acta Geodaetica et Geophysica, v. 52, n. 3, p. 345-356, 2017. DOI: 10.1007/s40328-016-0173-5.

ALMEIDA, M. S. Análise comparativa da qualidade posicional dos métodos de posicionamento por ponto preciso e do posicionamento relativo estático com GNSS. 2015. 127 p. Dissertação (Mestrado em Engenharia Civil) - Universidade Federal de Viçosa. Setor de Engenharia de Agrimensura e Cartográfica, Viçosa, MG, 2015.

ALTAMIMI, Z.; COLLILIEUX, X.; MÉTIVIER, L. Analysis and results of ITRF2008. (IERS Technical Note; 37) Frankfurt am Main: Verlag des Bundesamts für Kartographie und Geodäsie, 2012. 54 pp.

ALTAMIMI, Z.; REBISCHUNG, P.; MÉTIVIER, L.; COLLILIEUX, X. ITRF2014: A new release of the international terrestrial reference frame modeling nonlinear station motions. J. Geophys. Res. Solid Earth, v. 121, n. 8, p. 6109-6131, 2016. DOI: 10.1002/2016JB013098.

BRAGA, F. L. S.; DAL POZ, W. R. Mudança de referencial e atualização de coordenadas entre o IGS14 (ITRF2014) e o SIRGAS2000 (ITRF2000). In: SIMPÓSIO BRASILEIRO DE GEOMÁTICA, 4., Presidente Prudente, 2017. Anais... Presidente Prudente: UNESP, 2017. p .543-550.

BRAGA, F. L. S.; DAL POZ, W. R. Potencialidades do PPP no Software Bernese com Compatibilizações de Sistemas Geodésicos de Referência e de Tempo. Rev. Bras. Cartogr., v. 71, n. 3, p. 726-755, 2019. DOI: 10.14393/rbcv71n3-47483.

CARVALHO, A. S. Implicações do emprego de diferentes modelos de velocidades e parâmetros da transformação de Helmert no posicionamento geodésico na placa sul-americana. 188 p. Tese (Doutorado em Engenharia Civil) - Programa de Pós-Graduação em Engenharia Civil, Universidade Federal de Viçosa, Viçosa, 2015.

CARVALHO, A. S.; DAL POZ, W. R.; GRIPP JUNIOR, J.; LAROCCA, A. P. C.; KRUEGER, C. P. Systematization of the steps to Positional Determination in SIRGAS2000 based on ITRF(IGb08) Coordinates obtained by Online PPP Services. Revista Brasileira de Cartografia, v. 67, n. 1, p. 43-58, 2015.

CARVALHO, A. S.; DAL POZ, W. R.; LAROCCA, A. P. C. Compatibilização de referenciais de coordenadas e velocidades com estimativa de precisão. Boletim de Ciências Geodésicas, Curitiba, v. 21, n. 3, p. 590609, 2015. DOI: 10.1590/S1982-21702015000300033.

COSTA, S. M. A.; MANTOVANI, G.; SCOFANO, F.; LIMA, M. A. A.; SILVA, A. L.; MOURA JÚNIOR, N. J. Ampliação e modernização da RBMC. In: VII SIMPÓSIO BRASILEIRO DE CIÊNCIAS 
GEODÉSICAS E TECNOLOGIAS DA GEOINFORMAÇÃO, 2018, Recife. Anais do VII SIMGEO. p. 440-450.

DREWES H., HEIDBACH, O. The 2009 Horizontal Velocity Field for South America and the Caribbean. In: KENYON, S.; PACINO, M.C.; MARTI, U. (Eds.). Geodesy for Planet Earth. Buenos Aires: Springer, 2009. p. 657-664.

ESTEY, L. H.; MEERTENS. C. M. TEQC: The Multi-Purpose Toolkit for GPS/GLONASS Data. GPS Solutions. v. 3, n. 1, p. 42-49, 1999. DOI: 10.1007/PL00012778.

FRIDEZ, P. Bernese GNSS Software. Disponível em: <http://www.bernese.unibe.ch>. Acesso em: mai. 2020.

GHODDOUSI-FARD, R.; DARE, P. Online GPS processing services: an initial study. GPS Solut. v. 10, p. 12-20, 2006. DOI: 10.1007/s10291-005-0147-5.

GRINTER, T.; ROBERTS, C. Precise Point Positioning: Where are we now? In: INTERNATIONAL GLOBAL NAVIGATION SATELLITE SYSTEMS SOCIETY IGNSS SYMPOSIUM - IGNSS2011, 2011, Sydney. Proceedings of IGNSS2011. p. 15.

HOFMANN-WELLENHOF, B.; LICHTENEGGER, H.; WASLE, E. GPS Global Navigation Satellite Systems: GPS, GLONASS, GALILEO \& more. Austria: Springer Wien New York, 2008.

INFRAESTRUTURA NACIONAL DE DADOS ESPACIAIS (INDE). Estabelecido em 25 de fevereiro de 2015 o término do período de transição para o SIRGAS2000. 2020. Disponível em: <https://www.inde.gov.br/Noticias/Detalhe/22>. Acesso em: mai. 2020.

INSTITUTO BRASILEIRO DE GEOGRAFIA E ESTATÍSTICA (IBGE). Manual do Usuário - Aplicativo Online IBGE-PPP Versão: abril 2017. Disponível em: < https://biblioteca.ibge.gov.br/visualizacao/livros/liv101677.pdf>. Acesso em: jul. 2020.

INSTITUTO BRASILEIRO DE GEOGRAFIA E ESTATÍSTICA (IBGE). IBGE-PPP: Serviço on-line para Pós-Processamento de dados GNSS: manual do usuário. Versão Maio de 2020. Disponível em: < https://biblioteca.ibge.gov.br/visualizacao/livros/liv101677.pdf>. Acesso em: jul. 2020.

INSTITUTO BRASILEIRO DE GEOGRAFIA E ESTATÍSTICA (IBGE). Nota Técnica. Término do período de transição para adoção no Brasil do Sistema de Referência Geocêntrico para as Américas (SIRGAS), em sua realização de 2000,4 (SIRGAS2000), 2015. Disponível em: <http://geoftp.ibge.gov.br/metodos_e_outros_documentos_de_referencia/normas/nota_tecnica_termino_ periodo_transicao_sirgas2000.pdf $>$. Acesso em: mai. 2020.

INSTITUTO BRASILEIRO DE GEOGRAFIA E ESTATÍSTICA PPP (IBGE-PPP). Serviço online para pósprocessamento de dados GNSS - IBGE-PPP. 2020. Disponível em: < https://www.ibge.gov.br/geociencias/informacoes-sobre-posicionamento-geodesico/servicos-paraposicionamento-geodesico/16334-servico-online-para-pos-processamento-de-dados-gnss-ibgeppp.html?=\&t=saiba-mais-geociencias>. Acesso em: mai. 2020.

INTERNATIONAL TERRESTRIAL REFERENCE FRAME (ITRF). Call for participation. 2020. Disponível em: 〈http://itrf.ign.fr/doc_ITRF/CFP-ITRF2020.pdf〉. Acesso em: mai. 2020.

INTERNATIONAL GNSS SERVICE ANALYSIS CENTER COORDINATOR (IGSACC). Chronology of IGS Reference Frame Usage. 2020. Disponível em: <http://acc.igs.org/igs-frames.html>. Acesso em: mai. 2020.

LEICK, A. GPS Satellite Surveying. 3rd ed. Hoboken: John Wiley and Sons, 2004.

MACIUK, K.; SZOMBARA, S. Annual crustal deformation based on GNSS observations between 1996 and 2016. Arabian Journal of Geosciences, v. 11, n. 21, p. 1-12, 2018. DOI: 10.1007/s12517-018-4022-4.

MONICO, J. F. G. Posicionamento pelo GNSS: Descrição, fundamentos e aplicações. $2^{\mathrm{a}}$.ed. São Paulo: Editora UNESP, 2008. 476 p.

MOREIRA, D. M. Rede de referência altimétrica para avaliação da altimetria por satélites e estudos hidrológicos na região amazônica. 157 p. Dissertação (Mestrado em Engenharia Civil) - Programa de 
Pós-graduação em Engenharia Civil, Universidade Federal do Rio de Janeiro, Rio de Janeiro, 2010.

NASCIMENTO, L. A.; DAL POZ, W. R.; SANTOS, A. P.; FREITAS, K. X. S. Geração automatizada de séries temporais de dados posicionais utilizando o IBGE-PPP. Boletim de Ciências Geodésicas, v. 23, n. 1, p.150-165, 2017. DOI: 10.1590/S1982-21702017000100010.

NATURAL RESOURCES CANADA (NRCAN). CSRS-PPP: Canadian Spatial Reference System - Precise Point Positioning. 2020. Disponível em: <https://www.google.com/search?q=CSRS-PPP\&oq=CSRSPPP\&aqs=chrome..69i57j017.1576j0j4\&sourceid=chrome\&ie=UTF-8> . Acesso em: mai. 2020.

OLIVEIRA, G. D.; DAL POZ, W. R; ALMEIDA, M. S. Implementação de um sistema on-line para processamento de dados GNSS. Revista Brasileira de Cartografia, v. 71, n. 2, p. 501-512, 2019. DOI: $10.14393 /$ rbcv71n2-48184.

PETIT, G.; LUZUM, B. IERS Conventions (2010). IERS Technical Note $N^{\circ} 36$, Frankfurt am Main: Verlag des Bundesamts für Kartographie und Geodäsie, 2010. ISBN 3-89888-989-6.

R CORE TEAM. R: A language and environment for statistical computing. R Foundation for Statistical Computing, Vienna, 2019. Disponível em: <https://www.R-project.org/>. Acesso em: mar. 2020.

RAMOS, M. P.; DAL POZ, W. R.; CARVALHO, A. S. Análise das possibilidades de transformação de referencial e atualização de coordenadas estimadas pelo PPP. Boletim de Ciências Geodésicas, v. 22, n. 3, p.389-404. 2016. DOI: 10.1590/S1982-21702016000300022.

REBISCHUNG, P. [IGSMAIL-6663]. IGb08: an update on IGS08. 2012. Disponível em: <https://lists.igs.org/pipermail/igsmail/2012/000497.html>. Acesso em: mai. 2020.

REBISCHUNG, P. [IGSMAIL-7921] Switch to IGb14 reference frame. 2020. Disponível em: < https://lists.igs.org/pipermail/igsmail/2020/007917.html>. Acesso em: mai. 2020.

REDE BRASILEIRA DE MONITORAMENTO CONTÍNUO DOS SISTEMAS GNSS (RBMC). Dados diários e situação operacional. Disponível em: <https://www.ibge.gov.br/geociencias/informacoes-sobreposicionamento-geodesico/rede-geodesica/16258-rede-brasileira-de-monitoramento-continuo-dossistemas-gnss-rbmc.html?=\&t=dados-diarios-e-situacao-operacional>. Acesso em: mai. 2020.

SAPUCCI, L. F.; MONICO, J. F. G. Transformação de Helmert generalizada no posicionamento de alta precisão: fundamentação teórica e exemplificações. Brazilian Journal of Geophysics, Presidente Prudente-SP, v. 18, n. 2, p. 161-172. ago. 2001. ISSN 1809-4511.

SILVA, H. A.; MONICO, J. F. G. Análise de séries temporais de coordenadas GNSS. In: IV SIMPÓSIO BRASILEIRO DE CIÊNCIAS GEODÉSICAS E TECNOLOGIAS DA GEOINFORMAÇÃO, 2012, Recife. Anais do IV SIMGEO. p. 001-009.

SISTEMA DE REFERÊNCIA GEOCÊNTRICO PARA AS AMÉRICAS (SIRGAS). Sistema de Referência Geocêntrico para as Américas, Uso de velocidades no processamento de dados GNSS. 2020. Disponível em: <http://www.sirgas.org/pt/sirgas-con-network/velocity-model/using-velocities-gnss//>. Acesso em: fev. 2020.

UNIVERSITY NAVSTAR CONSORTIUM (UNAVCO). TEQC - The Toolkit for GNSS Data. 2020. Disponível em:<https://www.unavco.org/software/data-processing/teqc/teqc.html>. Acesso em: abr. 2020.

VENTORIM, B. G; DAL POZ, W. R. Avaliação do desempenho dos sistemas GPS e GLONASS no posicionamento por ponto preciso online, combinados e individualmente. Boletim de Ciências Geodésicas, Curitiba, v. 22, n. 2, p. 264-281. Abr-jun 2016. DOI: 10.1590/S1982-21702016000200015.

YIGIT, C. O.; GIKAS, V.; ALCAY, S.; CEYLAN, A. Performance evaluation of short to long term GPS, GLONASS and GPS/GLONASS postprocessed PPP. Survey Review, v. 46, n. 336, pp. 155-166, 2014. DOI: $10.1179 / 1752270613$ Y.0000000068. 


\section{Biografia do autor principal}

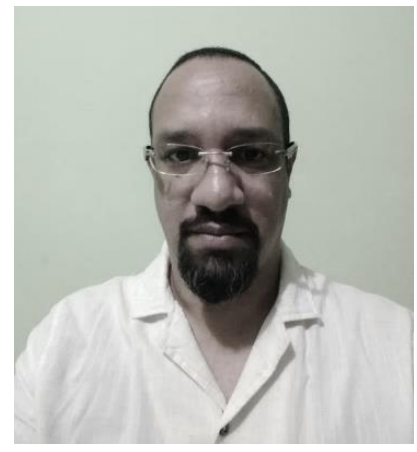

Lécio Alves Nascimento é natural de Itabuna, Bahia, Brasil. É Engenheiro Agrimensor e Cartógrafo pela Universidade Federal de Viçosa - UFV, mestre e doutorando em Informações Espaciais pelo Programa de Pós-Graduação em Engenharia Civil - PPGEC da UFV, Campus Viçosa. Atualmente é professor do Ensino Básico, Técnico e Tecnológico - EBTT no Instituto Federal de Ciência e Tecnologia do Norte de Minas Gerais - IFNMG, Campus Araçuaí. Atua nas áreas relacionadas a Agrimensura e às Geociências, onde desenvolve pesquisas relacionadas à Geodésia e Programação aplicada, cujos estudos concentram-se na Geodinâmica e deformações associadas ao efeito de carga hidrológica, modelagem e análises de séries temporais.

Esta obra está licenciada com uma Licença Creative Commons Atribuição 4.0 Internacional - CC BY. Esta licença permite que outros distribuam, remixem, adaptem e criem a partir do seu trabalho, mesmo para fins comerciais, desde que lhe atribuam o devido crédito pela criação original. 